\title{
Automated mineralogy based on micro-energy-dispersive X-ray fluorescence microscopy ( $\mu$-EDXRF) applied to plutonic rock thin sections in comparison to a mineral liberation analyzer
}

\author{
Wilhelm Nikonow and Dieter Rammlmair \\ Federal Institute for Geosciences and Natural Resources (BGR), Stilleweg 2, 30655 Hanover, Germany \\ Correspondence to: Wilhelm Nikonow (wilhelm.nikonow@bgr.de)
}

Received: 9 May 2017 - Discussion started: 7 June 2017

Revised: 31 August 2017 - Accepted: 12 September 2017 - Published: 18 October 2017

\begin{abstract}
Recent developments in the application of microenergy-dispersive X-ray fluorescence spectrometry mapping ( $\mu$-EDXRF) have opened up new opportunities for fast geoscientific analyses. Acquiring spatially resolved spectral and chemical information non-destructively for large samples of up to $20 \mathrm{~cm}$ length provides valuable information for geoscientific interpretation. Using supervised classification of the spectral information, mineral distribution maps can be obtained. In this work, thin sections of plutonic rocks are analyzed by $\mu$-EDXRF and classified using the supervised classification algorithm spectral angle mapper (SAM). Based on the mineral distribution maps, it is possible to obtain quantitative mineral information, i.e., to calculate the modal mineralogy, search and locate minerals of interest, and perform image analysis. The results are compared to automated mineralogy obtained from the mineral liberation analyzer (MLA) of a scanning electron microscope (SEM) and show good accordance, revealing variation resulting mostly from the limit of spatial resolution of the $\mu$-EDXRF instrument. Taking into account the little time needed for sample preparation and measurement, this method seems suitable for fast sample overviews with valuable chemical, mineralogical and textural information. Additionally, it enables the researcher to make better and more targeted decisions for subsequent analyses.
\end{abstract}

\section{Introduction}

Micro-energy-dispersive X-ray fluorescence microscopy ( $\mu$ EDXRF) is a new and versatile technique commonly used in various fields such as art (Keune et al., 2016), archeol- ogy (Kozak et al., 2016), biology (Figueroa et al., 2014), medicine (Wandzilak et al., 2015) and also with increasing extent in geosciences, mostly for visualization and quantification of element distributions (Belissont et al., 2016; Croudace and Rothwell, 2015; Flude and Storey, 2016; Gergely et al., 2016; Kéri et al., 2016; Lombi et al., 2011; Melcher et al., 2006; Poonoosamy et al., 2016; Rammlmair et al., 2001, 2006; Redwan et al., 2016). The combination of spatial and spectral information for large samples of up to $20 \mathrm{~cm}$ length with almost no sample preparation opens many fields of applications. It provides quick textural and chemical overview with spatially resolved main and trace element information (Nikonow and Rammlmair, 2016) at a relatively low cost and with easy operability compared to, for example, a scanning electron microscope (SEM). Applying supervised spectral classification, the chemical data can be used to derive mineral maps for quantitative petrography and the modal mineralogy (Nikonow and Rammlmair, 2016), which is key information for rock classification (Streckeisen, 1976).

Conventional automated mineralogy based on SEM and EDXRF is commonly used in different scientific fields, especially in the mining industry. It is applied in mineral and ore characterization or mineral processing (Fandrich et al., 2007; Sandmann, 2015; Sutherland and Gottlieb, 1991) and provides high-resolution data, but requires preparation of polished or thin sections, coating, a skilled operator and from several hours up to days for measurement. The mineral liberation analyzer (MLA) was developed in the last decade of the last century by Gu and Napier-Munn (1997) and dominated, together with QEMSCAN (Quantitative Evaluation of Minerals by Scanning Electron Microscopy; Sandmann, 2015), the market in the following years. It combines the in- 
formation of SEM with several EDX detectors. It uses the BSE (backscattered electrons) grey values to separate different grains and analyzes each identified grain center in order to provide the modal mineralogy and a set of quantitative geometric grain parameters $(\mathrm{Gu}, 2003)$.

For evaluation of modal analysis and automated mineralogy, three types of errors have to be taken into account (Solomon, 1963): the first is the false classification of a mineral, which is dependent on the operator-designed mineral database (operator error); the second is the 2-D effect, since 1-D information is extrapolated to a 2-D area (counting error); the third type of error is the 3-D effect resulting from extrapolation of the 2-D sample surface to the 3-D properties of the sample (sampling error). Being able to quantify these errors, the classification data becomes more reliable. Using $\mu$-EDXRF and spectral classification, the reliability of the classification algorithm can be measured by the classification thresholds. Mapping the whole sample surface will eliminate the 1-D extrapolation effect; only the extrapolation to the 3-D volume of the sample will remain, but it can be decreased by mapping large areas or series of rock slices or thin sections due to progress in measurement speed and partial automatization.

Assessment of 2-D classification data has been applied and discussed widely among remote sensing scientists. In most cases, hyperspectral images are evaluated by comparison to reference images (Foody, 2002), which are supposed to have true classification values (ground truth images), e.g., through manual control. Each pixel of the reference image is compared to the new classification, and the numbers of pixels assigned to each class are entered into an error matrix (or confusion matrix); the reference pixels are listed in columns and the new data in rows. The central diagonal represents the pixels that were assigned to the correct class; all others have been assigned to a different class. The classification's overall accuracy can be calculated by dividing the sum of the correctly classified pixels (central diagonal) by the total pixel number (Congalton, 1991).

In this work we evaluate the utility of $\mu$-EDXRF-based spectral classification and image analysis of thin sections using hyperspectral software (ENVI) for automated mineralogy compared to SEM + MLA.

\section{Material and methods}

\subsection{Samples}

Three polished thin sections of plutonic rocks from the collection of the Federal Institute for Geosciences and Natural Resources (BGR, Germany) were selected to be analyzed both with $\mu$-EDXRF and SEM + MLA. In addition, samples with different properties regarding mineral content and grain size were selected. Prior to this work, the thin sections were analyzed under a polarized light microscope and classified

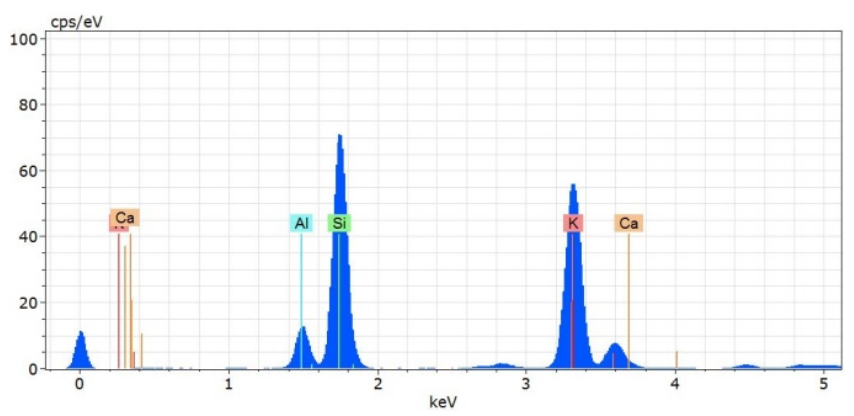

Figure 1. $\mu$-EDXRF spectrum of a $\mathrm{K}$ feldspar with the main constituents: $\mathrm{Al}(1.04 \mathrm{keV}), \mathrm{Si}(1,7 \mathrm{keV})$ and $\mathrm{K}(\mathrm{K} \alpha: 3,3 \mathrm{keV}, \mathrm{K} \beta$ : $3,6 \mathrm{keV})$.

as quartz diorite (sample 484), monzogranite (sample 342) and syenogranite (424) with varying mineral content regarding the main minerals quartz, feldspars, biotite, hornblende, and pyroxenes, as well as trace minerals such as magnetite, ilmenite, titanite, calcite, apatite, zircon and allanite. The thin section size is about $35 \times 23 \mathrm{~mm}$.

\subsection{Micro-energy-dispersive $X$-ray fluorescence microscopy $(\mu$-EDXRF)}

For $\mu$-EDXRF data acquisition, the M4 Tornado from Bruker was used. The X-ray radiation is generated by a tube with a a rhodium target operating with a maximum power of $30 \mathrm{~W}$. The polychromatic beam is focused by a polycapillary lens, resulting in a spot size of $17 \mu \mathrm{m}$ at $17.48 \mathrm{keV}$ (molybdenum (Mo) $\mathrm{K} \alpha$ ). In this work, the M4 Tornado is equipped with two silicon drift detectors facing each other at 180 and $90^{\circ}$ to the tube. The maximum tube excitation of $50 \mathrm{kV}$ and $600 \mu \mathrm{A}$ was chosen in order to differentiate elements with overlapping lines such as zircon, tin and barium, which have overlapping $\mathrm{L}$ lines with $\mathrm{K}$ lines of phosphorus, calcium and titanium, respectively. The thin sections were measured with a step size (i.e., pixel size) of $12 \mu \mathrm{m}$ and a dwell time of $2 \mathrm{~ms}$ per pixel. The total resolution of the measurement is about $2200 \times 1600$ pixels. The measurement takes about $3 \mathrm{~h}$ for one detector. In order to eliminate the effect of diffraction, the samples were measured with both detectors separately and the minimum intensity for each pixel was calculated and used for the classification. For more details regarding diffraction elimination see Nikonow and Rammlmair (2016). The measurement data were saved into a data cube, which contains a full spectrum for each measured pixel. With the M4 Tornado software, these results can be presented as element distribution maps with element intensities in false colors or grey scales. From these element maps, regions of interest can be selected and quantified chemically using the fundamental parameter approach. 
Table 1. Details of the M4 Tornado mapping and SEM + MLA measurement.

\begin{tabular}{llll}
\hline Device & M4 Tornado & MLA XBSE & MLA GXMAP \\
\hline Sample type & ca. $25 \times 35 \mathrm{~mm}$ thin section & $28 \times 38 \mathrm{~mm}$ thin section & $28 \times 38 \mathrm{~mm}$ thin section \\
Exciting energy & $50 \mathrm{kV}, 600 \mu \mathrm{A}$ & $25 \mathrm{kV}, 222 \mu \mathrm{A}$ & $25 \mathrm{kV}, 222 \mu \mathrm{A}$ \\
Step size & $12 \mu \mathrm{m}^{1}$ & grain centers & $6 \mu \mathrm{m}(\mathrm{EDX})^{1}$ \\
Dwell time per spot & $2 \mathrm{~ms}$ & $7 \mathrm{~ms}$ per grain & $7 \mathrm{~ms}$ \\
Measurement time & $6 \mathrm{~h}$ & $9-12 \mathrm{~h}$ & $40 \mathrm{~h}$ \\
\hline
\end{tabular}

${ }^{1}$ Continuous mapping. ${ }^{2}$ Grain segmentation by BSE - one EDX measurement per grain center.

Table 2. M4 Tornado chemical analysis of a K-feldspar spectrum from Fig. 1, EMPA from three different spots on K feldspar and literature value from Deer et al. (2013).

\begin{tabular}{lrrrrr}
\hline & M4 Tornado & EMPA 55/1 & EMPA 56/1 & EMPA 64/1 & Literature \\
\hline $\mathrm{SiO}_{2}$ & 63.57 & 64.30 & 63.77 & 63.53 & 64.66 \\
$\mathrm{TiO}_{2}$ & 0.40 & & & & 0.00 \\
$\mathrm{Al}_{2} \mathrm{O}_{3}$ & 21.65 & 18.13 & 18.62 & 18.16 & 19.72 \\
$\mathrm{Fe}_{2} \mathrm{O}_{3}$ & 0.22 & 0.18 & 0 & 0 & 0.08 \\
$\mathrm{MgO}$ & 0.66 & & & & 0.00 \\
$\mathrm{CaO}$ & 0.49 & & & & 0.34 \\
$\mathrm{Na}_{2} \mathrm{O}$ & 1.88 & 0.22 & 0.22 & 0.27 & 3.42 \\
$\mathrm{~K}_{2} \mathrm{O}$ & 11.09 & 15.90 & 16.29 & 15.61 & 11.72 \\
\hline $\mathrm{Sum}$ & 99.96 & 98.71 & 98.9 & 97.57 & 99.94 \\
\hline
\end{tabular}

\subsection{Scanning electron microscope (SEM) and mineral liberation analyzer (MLA)}

For comparison and validation of the $\mu$-EDXRF-based mineral classification and analysis, the SEM FEI Quanta 650F MLA-FEG was used. For this work, two modes of MLA were applied: (1) samples 424 and 342 were measured in the XBSE mode, where grains are classified and separated according to their grey level in the BSE image. Then, each separated grain is measured in the center with the X-ray detectors and classified chemically using a predefined mineral database. For the sample 484 the XBSE mode was not suitable, since the grey values of hornblende and biotite were too similar for a correct grain separation. Therefore, this sample was measured in (2) GXMAP mode. In this mode, grains are not separated by their grey values, but the whole sample was continuously mapped with an EDX analysis every $6 \mu \mathrm{m}$. The details of the SEM image acquisition are listed in Table 1. A detailed description of the functionality of MLA and the measuring modes can be found in the literature (Dobbe et al., 2009; Fandrich et al., 2007; Gu, 2003).

\subsection{Mineral classification of element distribution maps}

For analysis of the element distribution maps obtained by M4 Tornado, ENVI 5.1 by Exelis (Exelis Visual Information Solutions, 2015) was used. The supervised classification algorithm spectral angle mapper (SAM) (dos Reis Salles et al., 2016; Kruse et al., 1993) was applied on the 2-D data from M4 Tornado for the mineral classification. The classification algorithm allocates a mineral name to each pixel in the element distribution map according to a previously defined database of mineral spectra (endmember collection). It calculates the spectral similarity of two spectra, which is described by the angle between the vectors of both spectra. The angle of the spectral similarity can have values from 0 to $\pi / 2$ in radians (Masoumi et al., 2017). The vectors are in an $n$-dimensional space, where $n$ is the number of bands (here, element lines) (Masoumi et al., 2017). The SAM was developed for classification of hyperspectral images and is most widely applied in context with mineralogical classification (Van der Meer and De Jong, 2003; Girouard et al., 2004).

To establish the spectral database, thin sections were studied under a polarized light microscope. Some minerals were also analyzed by electron microprobe analysis (EMPA; Table 2; Sobańska, 2009). Knowing the mineral name and its location on the thin section, the spectra of the corresponding pixels of the EDXRF measurements were defined as mineral endmembers for the mineral database. Additionally, EDXRF spectra of selected areas such as mineral grains can be selected to calculate a sum spectrum and quantify the element ratios for a quantitative chemical analysis using the Bruker fundamental parameter algorithm. Figure 1 shows the spectrum of a $\mathrm{K}$ feldspar, and the quantification results are listed in Table 2, which match well the chemical data of a $\mathrm{K}$ feldspar from Deer et al. (2013). In comparison to EMPA data, light elements such as $\mathrm{Al}$ and $\mathrm{Na}$ seem to be slightly 

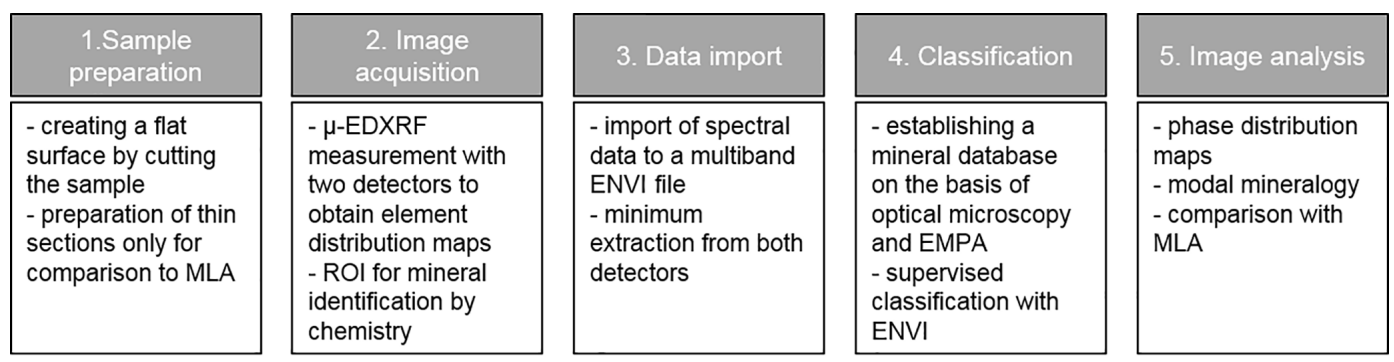

Figure 2. Block scheme for the workflow of the $\mu$-EDXRF analysis.

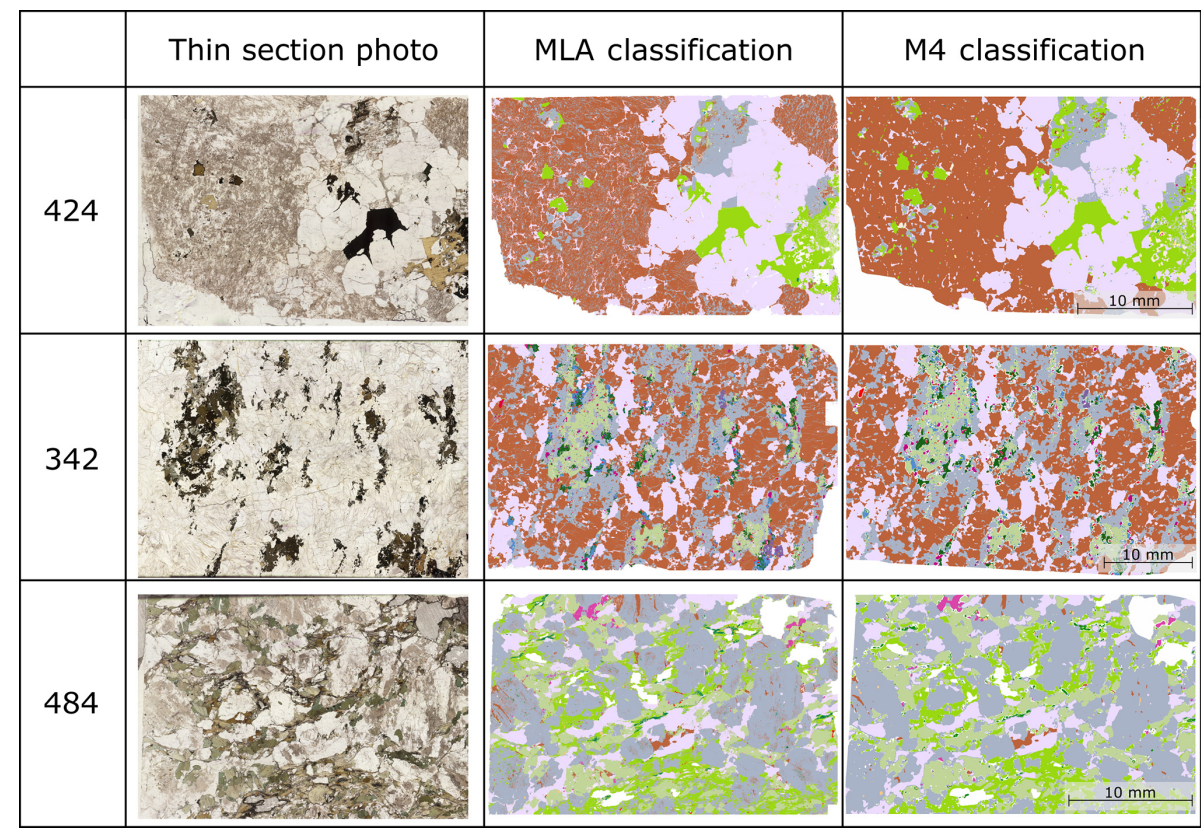

Figure 3. Thin section scan and classification results from mineral liberation analyzer (MLA) and M4 Tornado - ENVI. The size of thin sections 424 and 484 is about $30 \times 20 \mathrm{~mm}$; thin section 342 is about $40 \times 25 \mathrm{~mm}$; the color key for the classified minerals is displayed in Fig. 4.

overestimated by M4 Tornado quantification but are still in an identifiable range of a $\mathrm{K}$ feldspar. The workflow of the $\mu$ EDXRF measurement and following analysis is displayed in the block scheme of Fig. 2.

\section{Results: comparison between ENVI and MLA for plutonic rock thin sections}

For comparison and verification of the $\mu$-EDXRF-ENVI classification, three thin sections of plutonic rocks were analyzed and classified with ENVI and compared to MLA. The classification results and the mineral distribution maps are shown in Fig. 3; the modal mineralogy of both methods is listed in Table 3.

In general, the mineral distribution maps of both classifications correspond well with the thin section photo. Both methods recognized the present minerals. Single grains can be identified in thin section and both mineral distribution maps. Minerals that sometimes are difficult to differentiate in thin section microscopy such as quartz and plagioclase can be identified and separated using the chemical information, since plagioclase contains silicon as well as aluminum, sodium and calcium. Texture and grain structures of even complex intergrowth are recognizably well mapped. A few differences can be found in details: MLA is able to detect microstructures such as microperthitic intergrowth in sample 424 , due to the smaller beam diameter and the sampling depth limited to a few micrometers, whereas the data based on the M4 Tornado measurement integrate information of a $17 \mu \mathrm{m}$ spot size. In the ENVI classification of sample 342, clinopyroxene grains surrounded by plagioclase sometimes have small rims of hornblende. This is due to the overlap of both minerals producing mixed signals which are chemically similar to hornblende. The MLA data ( $6 \mu \mathrm{m}$ pixel size) were resized to an M4 pixel size of $12 \mu \mathrm{m}$ by combining 2 by 2 
Table 3. Modal mineralogy from the M4 classification in area-\% (MLA indicates thin section analyzed by MLA in XBSE mode, GX indicates MLA in GXMAP mode, M4 indicates thin section analyzed by the M4 Tornado. $<0.0$ means that the mineral was detected in a quantity less than one decimal.

\begin{tabular}{lrrrrrr}
\hline & $424 \mathrm{MLA}$ & $424 \mathrm{M} 4$ & $342 \mathrm{GX}$ & $342 \mathrm{M} 4$ & $484 \mathrm{MLA}$ & $484 \mathrm{M} 4$ \\
\hline Unclassified & 0.6 & $<0.0$ & $<0.0$ & $<0.0$ & 1.9 & $<0.0$ \\
Quartz & 36.0 & 33.0 & 20.0 & 19.9 & 15.3 & 11.4 \\
K feldspar & 39.6 & 44.7 & 42.1 & 42.3 & 3.3 & 0.9 \\
Plagioclase & 15.4 & 12.0 & 25.1 & 22.2 & 45.8 & 50.5 \\
Hornblende & 0.2 & 0.9 & 6.7 & 8.4 & 17.9 & 22.1 \\
Biotite & 7.6 & 8.6 & 0.1 & $<0.0$ & 13.8 & 13.9 \\
Calcite & 0.4 & 0.3 & $\mathrm{ND}$ & $\mathrm{ND}$ & 0.1 & $<0.0$ \\
Clinopyroxene & $\mathrm{ND}$ & $\mathrm{ND}$ & 1.6 & 2.2 & 0.1 & $<0.0$ \\
Orthopyroxene & $<0.0$ & $<0.0$ & 2.4 & 2.6 & $\mathrm{ND}$ & $\mathrm{ND}$ \\
Magnetite & $<0.0$ & $<0.0$ & 0.3 & 0.4 & 0.2 & $<0.0$ \\
Ilmenite & $\mathrm{ND}$ & $\mathrm{ND}$ & 0.8 & 0.9 & $\mathrm{ND}$ & $\mathrm{ND}$ \\
Titanite & $\mathrm{ND}$ & $\mathrm{ND}$ & $\mathrm{ND}$ & $\mathrm{ND}$ & 1.0 & 0.6 \\
Apatite & $<0.0$ & $<0.0$ & 0.3 & 0.2 & 0.5 & 0.3 \\
Zircon & 0.1 & $<0.0$ & 0.2 & 0.1 & $<0.0$ & $<0.0$ \\
Allanite & $<0.0$ & $<0.0$ & 0.4 & 0.4 & $<0.0$ & $<0.0$ \\
\hline
\end{tabular}

pixels (nearest neighbor) for technical reasons and image to image registration (Table 4). To compare both classifications in detail, an error matrix was calculated with ENVI. The error matrix shows fair overall accuracy of $76 \%$. There seem to be three classes of accuracy: the first class, with good accuracy of about $80 \%$, consists of K feldspar, quartz, allanite and hornblende. The second class, with fair to medium accuracy between 60 and $70 \%$, consists of ilmenite, plagioclase and orthopyroxene. Minerals with low accuracy are clinopyroxene, which is mostly confused with hornblende; and magnetite, zircon and apatite, which are mostly unclassified in MLA.

For a detailed visual comparison of both classifications, a section of sample 342 is shown in Fig. 4. As mentioned before, small plagioclase veins cannot be identified with the M4 Tornado; it is also noticeable that some minerals such as allanite, ilmenite or orthopyroxene have small unclassified (white) rims in the ENVI map, which is due to the mixed fluorescence signals coming from a different depth in the M4 Tornado measurement. Separation of clinopyroxene and hornblende is difficult, because both minerals are chemically similar. Main elements such as silicon, calcium and iron are present in both minerals, and other elements such as aluminum, potassium or titanium have very low X-ray fluorescence intensities in the M4 Tornado measurement due to their low content or low atomic number. Nevertheless, the grain outlines in general are comparable.

\section{Discussion}

The proposed method depends mainly on the correct mineral classification. The key is to create a comprehensive mineral database that contains all present minerals and is able to distinguish minerals of similar spectral features. Having information about the geological system of the sample and the possible paragenesis will improve the classification and decrease the occurrence of unclassified areas. Since many minerals are parts of solid solution series, e.g., plagioclase, pyroxene or biotite, the mineral database can consist of several endmembers of one mineral group in order to classify chemical changes within one solid solution series.

Isochemical minerals such as rutile, anatase and brookite $\left(\mathrm{TiO}_{2}\right)$ are not distinguishable with an M4 Tornado measurement. Only with further information from other methods such as Raman spectroscopy or X-ray diffraction could more information about the crystal system be obtained and used for the classification. Until then, identification of the mineral is based on the chemical information. However, the classification can be extended from mineral groups to mineral endmembers easily, when more detailed information is available. The rock classification should "grow with the science" (Carr and Hibbard, 1991).

A similar problem creates the range of detectable elements. Since the lightest detectable element is sodium, minerals that contain lighter elements are not clearly identifiable. Apatite, for example, can be identified by the abundance of phosphorus, calcium and possibly chlorine. Distinguishing between fluorapatite and hydroxylapatite is not possible with this method. Therefore, the group name apatite should be used. A special case is iron. If there is a mineral containing iron solely, there are several possibilities: the iron oxides magnetite and hematite would fit the chemical data since oxygen is not detectable. The presence of titanium would indicate magnetite or titanomagnetite. Iron hydroxide and oxide-hydroxide fit the chemical data, too, as well as siderite (iron carbonate). Little amounts of calcium, mag- 
Table 4. Error matrix in percent for sample 342 with the MLA as reference data in the columns and the $\mu$-EDXRF in lines with mineral abbreviations as follows: unclassified, Uncl.; clinopyroxene, Cpx; hornblende, Hbl; allanite, Aln; magnetite, Mag; ilmenite, Ilm; quartz, Qtz; K feldspar, Afs; zircon, Zrn; apatite, Ap; orthopyroxene, Opx.

\begin{tabular}{lrrrrrrrrrrrr|r}
\hline Class & Uncl. & Cpx & Hbl & Aln & Mag & Ilm & Qtz & Pl & Afs & Zrn & Ap & Opx & Total \\
\hline Uncl. & 58.21 & 6.54 & 5.84 & 8.21 & 20.06 & 17.93 & 8.36 & 8.26 & 6.17 & 40.9 & 19.11 & 11.77 & 9.68 \\
Cpx & 0.42 & 38.18 & 11.24 & 3.08 & 7 & 0.91 & 0.52 & 1.71 & 0.12 & 8.7 & 5.76 & 6.96 & 2.11 \\
Hbl & 1.14 & 38.22 & 77.92 & 3.04 & 20.91 & 5.81 & 1.34 & 4.92 & 0.45 & 5.45 & 11.5 & 10.56 & 7.63 \\
Aln & 0.02 & 0.06 & 0.01 & 79.96 & 0.07 & 0.16 & 0.05 & 0.06 & 0.03 & 0.02 & 0.49 & 0.01 & 0.32 \\
Mag & 0.04 & 0.54 & 0.42 & 0.02 & 41.77 & 9.89 & 0.02 & 0.27 & 0.03 & 1.57 & 1.66 & 1.92 & 0.34 \\
llm & 0.12 & 0.56 & 0.45 & 1.57 & 0.6 & 63.96 & 0.1 & 0.71 & 0.08 & 7.22 & 6.9 & 0.51 & 0.78 \\
Qtz & 3.75 & 0.43 & 0.05 & 0.25 & 0.14 & 0.07 & 79.55 & 4.48 & 3.8 & 0.74 & 0.57 & 0.25 & 18.01 \\
Pl & 13.63 & 1.9 & 1.02 & 2.16 & 1.72 & 0.54 & 6.47 & 66.13 & 5.04 & 10.71 & 15.82 & 0.59 & 20.07 \\
Afs & 22.13 & 0.04 & 0.04 & 0.19 & 0.19 & 0.02 & 3.13 & 12.37 & 84.11 & 1.54 & 0.95 & 0.06 & 38.49 \\
Zrn & 0 & 0.04 & 0.01 & 0.26 & 0.02 & 0.02 & 0.02 & 0.07 & 0.03 & 20.21 & 0.44 & 0 & 0.06 \\
Ap & 0.04 & 0.31 & 0.38 & 0.51 & 0.01 & 0.03 & 0.03 & 0.25 & 0.04 & 1.19 & 22.54 & 0.01 & 0.18 \\
Opx & 0.5 & 13.17 & 2.61 & 0.74 & 7.53 & 0.67 & 0.4 & 0.76 & 0.12 & 1.77 & 14.27 & 67.36 & 2.33 \\
\hline Total & 100 & 100 & 100 & 100 & 100 & 100 & 100 & 100 & 100 & 100 & 100 & 100 & 100 \\
\hline
\end{tabular}
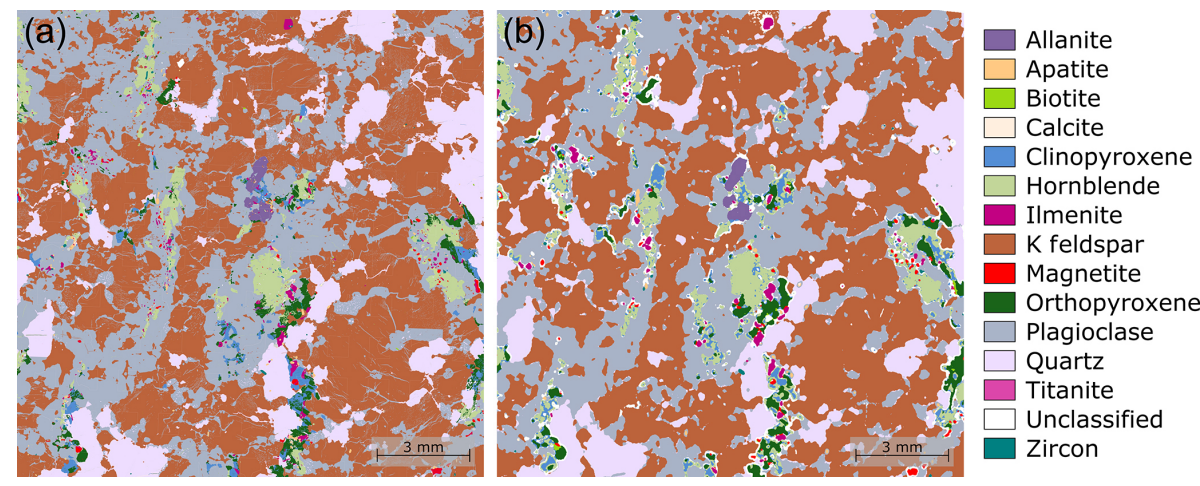

Figure 4. Detailed view of a section in the upper right corner of sample 342: mineral distribution map from MLA (a) and ENVI (b).

nesium or manganese would indicate the iron carbonate, but several possibilities still remain for iron.

Furthermore, the resolution limits of each device have to be taken into account. Looking at the modal analysis, differences occur mostly from the estimation of quartz and plagioclase and the intimate intergrowth of feldspars. According to the MLA measurement, sample 484 contains about $5 \%$ less plagioclase than what the M4 classification determined. These differences result from the microperthitic intergrowth of the sample. The perthite shows small lamellae of plagioclase in the K-feldspar host. When these lamellae are smaller than the beam diameter of $17 \mu \mathrm{m}$, the pixel is classified as an alkali feldspar with elevated sodium and calcium content, while a small fraction of plagioclase is lost in the modal mineralogy. Similarly, differences can occur from other mineral combinations or overlaps in one pixel, which may even result in a different mineral classification or in unclassified grain boundaries. Plagioclase overlapping with pyroxene can be chemically similar to hornblende and result in a small horn- blende rim between plagioclase and pyroxene grains. Minerals with low classification accuracy, compared to MLA, such as zircon, magnetite and apatite, are present mostly as small and single grains surrounded by plagioclase. This results in an unclassified rim due to overlapping signals of both minerals. Because of the small grain sizes, a number of unclassified border pixels form a relatively large proportion compared to the number of core pixels and, therefore, result in a very low classification accuracy.

Comparing the M4 classification procedure to MLA, some difficulties should be mentioned. With MLA, differentiation of minerals with a similar average atomic number is difficult when the measurement should involve all rock-forming and accessory minerals from very low to very high average atomic numbers. The grey values are a function of the average atomic number of the mineral, and the XBSE mode uses the grey values of the BSE image for grain separation. The grain separation in XBSE mode is based on the grey value of the BSE image. Minerals of similar atomic number will 
be eventually combined (e.g., plagioclase-quartz-muscovite or biotite-hornblende-pyroxene), and only one measurement in the center of the particle will be performed. Contrast and brightness of the BSE images are adapted for the present mineral assemblage. If a good contrast for distinction of light minerals (dark in BSE) such as quartz and plagioclase were needed, the grey level spectrum would be stretched in the lower region to differentiate light minerals. Consequently, heavier minerals such as allanite or zircon would appear white, and adjacent minerals of equal grey value would be identified as one grain and would not be separated. Therefore, it was necessary to measure the thin section of sample 484 in GXMAP mode, which increased the measuring time from 12 to $40 \mathrm{~h}$. Another source of error was found to be the frame overlapping. Some frames are shifted apart, and the automatic particle joining had to be corrected manually several times.

The combination of $\mu$-EDXRF and hyperspectral classification shows good applicability for heavy accessory minerals and sulfide ores, since heavy elements are easy to detect due to their good fluorescence response. Even small grains of accessories can be detected, since the EDXRF mapping provides spatially resolved data. If there is a sample area of $20 \times 15 \mathrm{~cm}$ with just one gold grain large enough to detect, the element distribution map will show the gold grain. ENVI offers the possibility of locating such minor minerals of interest and providing the pixel coordinates of each grain of interest. Furthermore, the mineral distribution maps offer opportunities to perform image analysis, e.g., for calculation of geometric grain parameters (Nikonow and Rammlmair, 2016).

An important factor to consider for scientist and laboratories is the financial aspect, such as purchase and maintenance costs as well as easy handling and usability of the devices. In this case, the financial advantage is on the side of the $\mu$-EDXRF. The acquisition costs for the $\mu$-EDXRF including two detectors and the software (ENVI) is about EUR 250 000, whereas the SEM including the MLA software may be around 4 times higher. To operate the SEM, high vacuum pumps and a nitrogen supply are necessary in addition to a skilled operator, whereas the $\mu$-EDXRF can operate at atmospheric pressure or in low vacuum and is relatively easy to operate for scientists and also students. Both devices should preferably be operated in an air-conditioned laboratory; however, in this work the $\mu$-EDXRF was not in an air-conditioned room.

Taking into account the limits and potentials of both methods, it is important to analyze the question or the problem the data should answer or solve. If the samples have fine intergrowths or small grains that need to be resolved in high detail, the spot size of $17 \mu \mathrm{m}$ might be too large. Also if the presence of light elements such as carbon and oxygen needs to be known, other methods such as MLA should be preferred. On the other hand, the big advantage of $\mu$-EDXRF is the little preparation and measuring time required. It is possible to have chemical information of a large sample area hours after having taken the samples. Whereas chemical analysis can take days to pulverize or digest the samples, EDXRF mapping can give a good overview in a short time period, although within a certain error limit. Moreover, the sample stays intact for further analyses. For detailed chemical analysis either the bulk sample has to be processed or small areas or minerals have to be separated, which is very timeconsuming. $\mu$-EDXRF provides spatially resolved chemical data, and therefore even small areas of interest can be analyzed separately. For microscopy and petrographic analysis thin sections have to be prepared, which are limited in most cases to an area of a few $\mathrm{cm}^{2}$. Microscopy is very helpful, but it can be advantageous to be able to see more than a few thin sections. Since the EDXRF maps are fast to obtain, depending on the size and chosen acquisition time, results can be obtained within minutes or several hours.

\section{Conclusions}

In this work we describe the multispectral classification of plutonic rock thin sections based on $\mu$-EDXRF data. The SAM classification was shown to work well for primary, mostly unweathered plutonic rocks. Compared to MLA, the mineral classification results correspond well on thin sections. Problems arise due to the technical limits of the used $\mu-$ EDXRF instrument including resolution and not-measurable elements, whereas a lot of valuable information of even larger samples than thin section size can be obtained faster with multispectral classification.

This method is suitable for obtaining a fast sample overview with chemical, textural and mineralogical information, and even geometric grain information, as it works nondestructively and covers an area of $20 \times 15 \mathrm{~cm}$. Therefore, it can be seen as the first step in a series of geoscientific analyses providing a large scale overview, while the samples remain intact. This method can help in choosing the areas of interest for more detailed measurements, thin section preparation, MLA, or other high-resolution or bulk geochemical analyses. Having spatial and chemical information about the samples can decrease the number of thin sections that need to be prepared or the following chemical analyses, since the choice can be made more targeted and systematic. Overall, it is an objective, repeatable, and quantifiable way for modal mineralogy and petrographic image analysis.

Data availability. Raw data are available upon request from the corresponding author.

Competing interests. The authors declare that they have no conflict of interest. 
Acknowledgements. The results of this work are part of research that is funded by the German Federal Ministry of Education and Research (BMBF) within the project SecMinStratEl (grant no. 033R118B). The authors are thankful to Jeannet Meima for the many helpful comments on the manuscript, Katarzyna Krasniqi for parts of the mineral database, Dominic Göricke for technical support with the SEM and Gerhard Heide from the TU Bergakademie Freiberg for the fruitful discussions.

Edited by: Lev Eppelbaum

Reviewed by: two anonymous referees

\section{References}

Belissont, R., Muñoz, M., Boiron, M.-C., Luais, B., and Mathon, O.: Distribution and oxidation state of $\mathrm{Ge}, \mathrm{Cu}$ and $\mathrm{Fe}$ in sphalerite by $\mu$-XRF and K-edge $\mu$-XANES: insights into Ge incorporation, partitioning and isotopic fractionation, Geochim. Cosmochim. Acta, 177, 298-314, 2016.

Carr, J. R. and Hibbard, M.: Open-ended mineralogical/textural rock classification, Comput. Geosci., 17, 1409-1463, 1991.

Congalton, R. G.: A review of assessing the accuracy of classifications of remotely sensed data, Remote Sens. Environ., 37, 35-46, 1991.

Croudace, I. W. and Rothwell, R. G.: Micro-XRF Studies of Sediment Cores: Applications of a non-destructive tool for the environmental sciences, Springer, 2015.

Deer, W., Howie, R., and Zussman, J.: An introduction to the rockforming minerals, The Mineralogical Society, London, 2013.

Dobbe, R., Gottlieb, P., Gu, Y., Butcher, A., Fandrich, R., and H, L.: Scanning Electron Beam-Based Automated Mineralogy-Outline of Technology and selected applications in the Natural Resources Industry, 11th European Workshop on Modern Development and Applications in Microbeam Analysis, Gdynia/Rumia, Gdansk, Poland, 169-189, 2009.

dos Reis Salles, R., de Souza Filho, C. R., Cudahy, T., Vicente, L. E., and Monteiro, L. V. S.: Hyperspectral remote sensing applied to uranium exploration: A case study at the Mary Kathleen metamorphic-hydrothermal U-REE deposit, NW, Queensland, Australia, Journal of Geochemical Exploration, 179, 36-50, 2016.

Exelis Visual Information Solutions, I., a subsidiary of Harris Corporation: ENVI, 2015.

Fandrich, R., Gu, Y., Burrows, D., and Moeller, K.: Modern SEMbased mineral liberation analysis, Int. J. Miner. Process., 84, 310-320, 2007.

Figueroa, R., Lozano, E., Belmar, F., Alcaman, D., Bohlen, A., Oliveira, C., Silva, A., and Veloso, J.: Characteristics of a robust and portable large area X-ray fluorescence imaging system, X-Ray Spectrometry, 43, 126-130, 2014.

Flude, S. and Storey, M.: 40Ar/39Ar age of the Rotoiti Breccia and Rotoehu Ash, Okataina Volcanic Complex, New Zealand, and identification of heterogeneously distributed excess $40 \mathrm{Ar}$ in supercooled crystals, Quaternary Geochronology, 33, 13-23, 2016.

Foody, G. M.: Status of land cover classification accuracy assessment, Remote Sens. Environ., 80, 185-201, 2002.

Gergely, F., Osán, J., Szabó, B. K., and Török, S.: Analytical performance of a versatile laboratory microscopic X-ray fluorescence system for metal uptake studies on argillaceous rocks, Spectrochimica Acta Part B: Atomic Spectroscopy, 116, 75-84, 2016.

Girouard, G., Bannari, A., El Harti, A., and Desrochers, A.: Validated spectral angle mapper algorithm for geological mapping: comparative study between QuickBird and Landsat-TM, XXth ISPRS congress, geo-imagery bridging continents, Istanbul, Turkey, 12-23, 2004.

$\mathrm{Gu}$, Y.: Automated scanning electron microscope based mineral liberation analysis An introduction to JKMRC/FEI mineral liberation analyser, Journal of Minerals and Materials Characterization and Engineering, 2, 33, 2003.

$\mathrm{Gu}$, Y. and Napier-Munn, T.: JK/Philips mineral liberation analyzer - an introduction, Proceedings of the Minerals Processing'97 Conference, Cape Town, SA, p. 2, 1997.

Kéri, A., Osán, J., Fábián, M., Dähn, R., and Török, S.: Combined X-ray microanalytical study of the Nd uptake capability of argillaceous rocks, X-Ray Spectrometry, 45, 54-62, 2016.

Keune, K., Mass, J., Mehta, A., Church, J., and Meirer, F.: Analytical imaging studies of the migration of degraded orpiment, realgar, and emerald green pigments in historic paintings and related conservation issues, Heritage Sci., 4, 1-14, https://doi.org/10.1186/s40494-016-0078-1, 2016.

Kozak, L., Niedzielski, P., Jakubowski, K., Michałowski, A., Krzyżanowska, M., Teska, M., Wawrzyniak, M., Kot, K., and Piotrowska, M.: The XRF mapping of archaeological artefacts as the key to understanding of the past, Journal of X-Ray Science and Technology, 24, 1-9, 2016.

Kruse, F., Lefkoff, A., Boardman, J., Heidebrecht, K., Shapiro, A., Barloon, P., and Goetz, A.: The spectral image processing system (SIPS) - interactive visualization and analysis of imaging spectrometer data, Remote Sens. Environ., 44, 145-163, 1993.

Lombi, E., de Jonge, M. D., Donner, E., Ryan, C. G., and Paterson, D.: Trends in hard X-ray fluorescence mapping: environmental applications in the age of fast detectors, Anal. Bioanal. Chem., 400, 1637-1644, 2011.

Masoumi, F., Eslamkish, T., Honarmand, M., and Abkar, A. A.: A Comparative Study of Landsat-7 and Landsat-8 Data Using Image Processing Methods for Hydrothermal Alteration Mapping, Resource Geology, 67, 72-88, 2017.

Melcher, F., Oberthür, T., and Rammlmair, D.: Geochemical and mineralogical distribution of germanium in the Khusib Springs $\mathrm{Cu}-\mathrm{Zn}-\mathrm{Pb}-\mathrm{Ag}$ sulfide deposit, Otavi Mountain Land, Namibia, Ore Geology Reviews, 28, 32-56, 2006.

Nikonow, W. and Rammlmair, D.: Risk and benefit of diffraction in Energy Dispersive X-ray fluorescence mapping, Spectrochimica Acta Part B: Atomic Spectroscopy, 125, 120-126, 2016.

Poonoosamy, J., Curti, E., Kosakowski, G., Grolimund, D., Van Loon, L. R., and Mäder, U.: Barite precipitation following celestite dissolution in a porous medium: A SEM/BSE and $\mu$ XRD/XRF study, Geochim. Cosmochim. Acta, 182, 131-144, 2016.

Rammlmair, D., Tacke, K., and Jung, H.: Application of new XRFscanning techniques to monitor crust formation in column experiments, Securing the Future, Proceedings of the International Conference on Mining and the Environment, Skellefteå, 683692, 2001.

Rammlmair, D., Wilke, M., Rickers, K., Schwarzer, R., Möller, A., and Wittenberg, A.: Geology, mining, metallurgy, Handbook of 
Practical X-Ray Fluorescence Analysis, Springer, Heidelberg, 2006, 640-687, 2006.

Redwan, M., Rammlmair, D., and Nikonow, W.: Application of quantitative mineralogy on the neutralization-acid potential calculations within $\mu \mathrm{m}$-scale stratified mine tailings, Environ. Earth Sci., 76, p. 46, 2016.

Sandmann, D.: Method development in automated mineralogy, Dr. rer. nat. Dissertation, Fakultät für Geowissenschaften, Geotechnik und Bergbau, Technische Universität Bergakademe Freiberg, 176 pp., 2015.

Sobańska, K.: Geneza pegmatytów miarolitycznych z okolic Strzegomia, 2009, Magister Thesis, Institute of Geology, Adam Mickiewicz University in Poznan, 100 pp., 2009.

Solomon, M.: Counting and sampling errors in modal analysis by point counter, J. Petrol., 4, 367-382, 1963.

Streckeisen, A.: To each plutonic rock its proper name, Earth Sci. Rev., 12, 1-33, 1976.
Sutherland, D. N. and Gottlieb, P.: Application of automated quantitative mineralogy in mineral processing, Miner. Eng., 4, 753$762,1991$.

Van der Meer, F. and De Jong, S.: Spectral mapping methods: many problems, some solutions, 13-16, Proceedings of the 3rd EARSeL workshop on imaging spectroscopy, Herrsching, Germany, 13-16 May 2003, edited by: Habermeyer, M., Mülle, A., and Holzwarth, S., EARSeL, 146-162, EARSEL, 2003.

Wandzilak, A., Czyzycki, M., Radwanska, E., Adamek, D., Geraki, K., and Lankosz, M.: X-ray fluorescence study of the concentration of selected trace and minor elements in human brain tumours, Spectrochimica Acta Part B: Atomic Spectroscopy, 114, 52-57, 2015. 